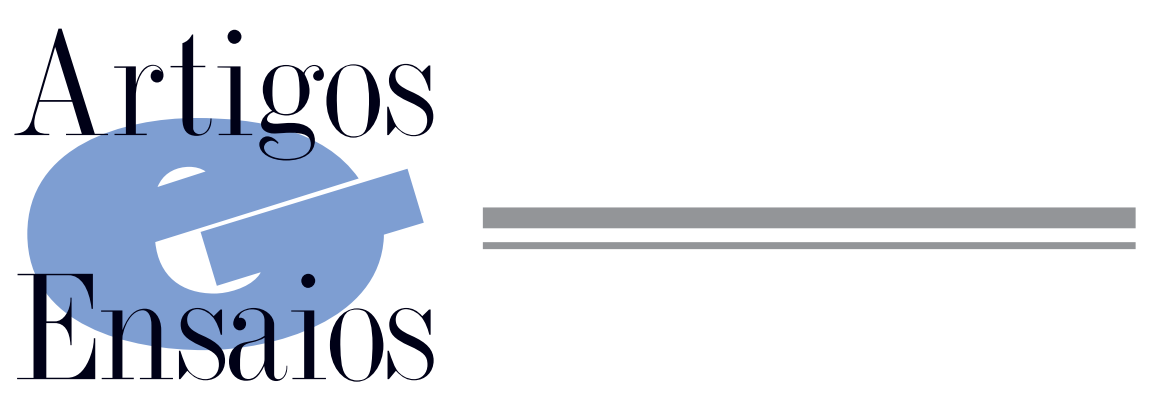

\section{A COR NA RIBALTA}

\section{Petrônio Domingues}

Em dezembro de 1948, o famoso dramaturgo Nelson Rodrigues concedeu uma entrevista ao jornal Quilombo. Perguntado a que ele atribuía o afastamento do negro dos palcos brasileiros, respondeu: "- Acho, isto é, tenho a certeza de que é pura e simples questão de desprezo. Raras companhias gostam de ter negro em cena; e quando uma peça exige o elemento de cor, adota-se a seguinte solução: brocha-se um branco. Branco pintado - eis o negro do teatro nacional". Em seguida, Nelson Rodrigues não hesitava em dizer: "É preciso uma ingenuidade perfeitamente obtusa ou uma má fé cínica para se negar a existência do preconceito racial nos palcos brasileiros. Os artistas de cor, ou fazem moleques gaiatos, ou carregam bandeja ou, por último, ficam de fora" (1).

Foi justamente para se contrapor à situação descrita por Nelson Rodrigues que foi criado o Teatro Experimental do Negro (TEN), no Rio de Janeiro, em 1944. Em outras palavras, o TEN foi um protesto contra a exclusão do negro dos palcos brasileiros ou contra sua inclusão marginal, em papéis subalternos ou decorativos. Quando uma peça reservava um papel de destaque para o negro, ele geralmente era interpretado por um ator branco, que pintava o rosto de preto.

Mas como o TEN entrou em cena? No início da década de 1940, Abdias do Nascimento - um afrobrasileiro nascido em Campinas (SP), ex-militar, agitador cultural e ativista político, com passagem pelo movimento integralista, o fascismo à brasileira - empreendeu uma campanha pela criação de um grupo de teatro negro. Inicialmente, ele apresentou a ideia de soerguimento desse teatro em São Paulo, mas não encontrou apoio no meio negro e intelectual. Até mesmo Mário de Andrade, escritor modernista, teria recusado o convite de ajudá-Io na empreitada. Já no Rio de Janeiro, Abdias assistiu a uma conferência do teatrólogo Pascoal Carlos Magno, em que este indicava a necessidade da emergência do teatro negro no Brasil. Abdias, então, sentiu-se mais motivado e passou a convocar reuniões preparatórias. A primeira "reunião" teria sido no Café Amarelinho, na Cinelândia, com Aguinaldo Camargo, Wilson Tibério, Teodorico dos Santos e José Herbel. A segunda teria ocorrido nas acomodações do teatro Fênix. Assim, em 13 de outubro de 1944 nascia o Teatro Experimental do Negro. Com a fundação, veio o primeiro problema: onde funcionaria a nova companhia? Com a intermediação de um amigo, Aníbal Machado, conseguiu-se o empréstimo dos salões da União Nacional do Estudante (UNE), na praia do Flamengo (2). O curso inaugural de teatro oferecido pelo grupo foi auspicioso. Com o tempo, a companhia teatral reunia mais de uma dezena de atores fixos. Diante da ausência de peças no país que retratasse dignamente a situação do afrobrasileiro, o TEN decidiu encenar O imperador Jones, peça de Eugene O'Neill, o consagrado dramaturgo modernista estadunidense. Sua estreia ocorreu no dia 8 de maio de 1945, no mais importante teatro carioca: o Teatro Municipal. Era a primeira vez que um negro pisava naquele palco interpretando a personagem principal de uma montagem do teatro moderno. O grupo só teria conseguido se apresentar naquele local por ordem do próprio presidente Getúlio Vargas.

A peça O imperador Jones foi a primeira de uma série de produções através das quais, por alguns anos, o TEN conse- 


\section{Artigos \& Ensaios}

guiu agitar a cena teatral do Rio de Janeiro (3). Da década de 1940 a 1950, o grupo montou vários espetáculos, como o Moleque sonhador, do mesmo Eugene O 'Neill, e Calígula, de Albert Camus. Em 1961, organizou e publicou a antologia Dramas para negros e prólogos para brancos, reunindo tanto as peças que foram escritas especialmente para o grupo quanto algumas outras que abordavam a vida do negro. A antologia incluía as peças Anjo negro, de Nelson Rodrigues, e O emparedado, de Tasso da Silveira (4).

Outras peças foram escritas a partir da experiência do TEN, ou seja, foram enredos produzidos com a finalidade de serem interpretados por um elenco negro. Entre eles, vale mencionar Orfeu da Conceição, de Vinicius de Morais; O cavalo e o santo, de Augusto Boal; O processo do

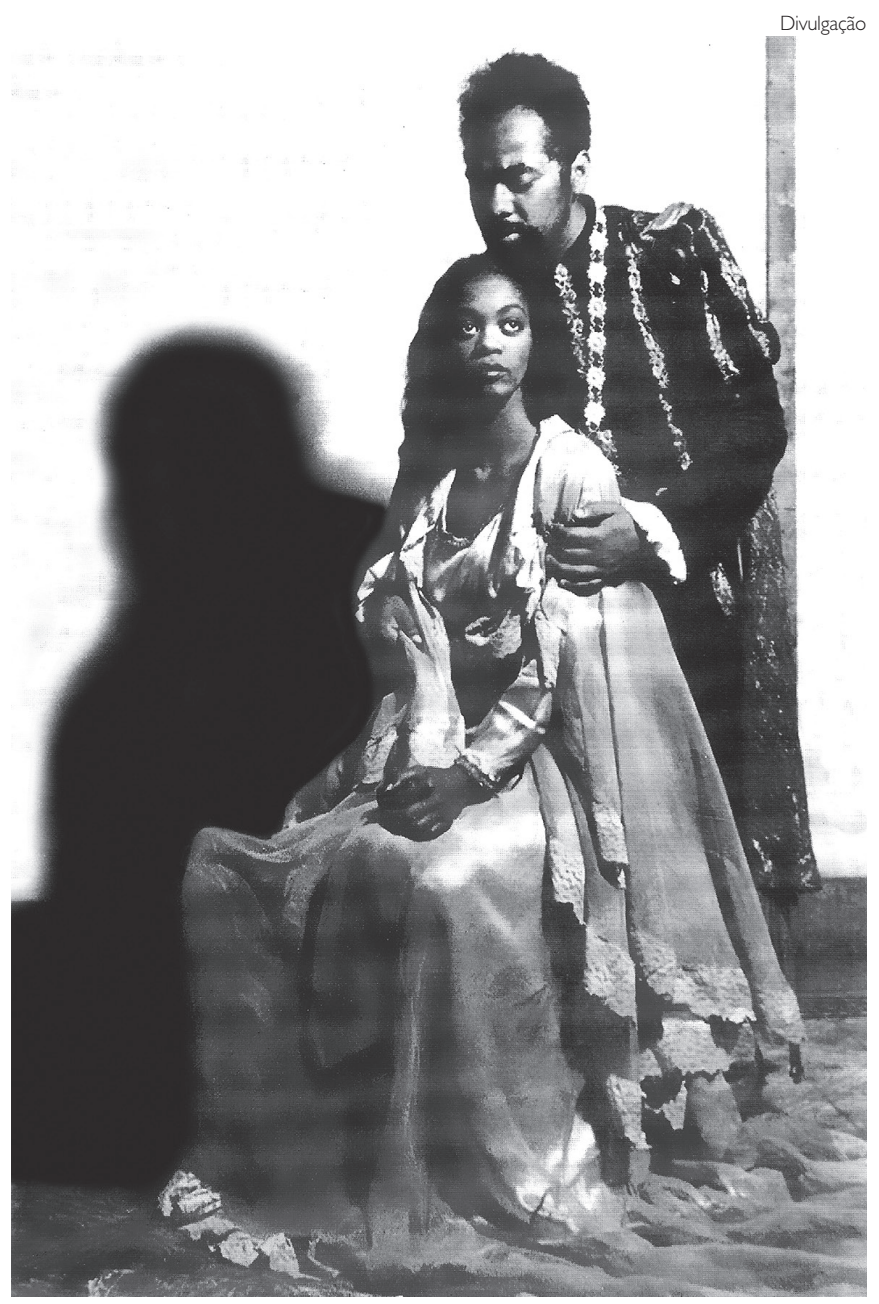

Ruth de Souza e Abdias do Nascimento em Otelo, no Festival Shakespeare. Teatro Fênix (RJ), 1949 o grupo teatral, afinal, havia a necessidade de saber ler para decorar e encenar as peças. Os inscritos eram, sobretudo, trabalhadores em posições subalternas, estudantes, funcionários públicos e empregadas domésticas.

Em 1948, o TEN iniciou a publicação de Quilombo, jornal que trazia um subtítulo bastante sugestivo: Vida, problemas e aspirações do negro. Funcionando como veículo de divulgação das ideias, dos sonhos e das expectativas do grupo, o periódico trouxe várias notas de aniversários, casamentos, formaturas e festas; destacou a participação do negro no esporte e nas artes (música, teatro, dança, literatura e cinema); estabeleceu intercâmbio com o "movimento associativo dos homens de cor", nacional e internacional; contou (e celebrou) a memória histórica dos grandes vultos de Cristo negro, de Ariano Suassuna; Pedro Mico, de Antônio Callado; Gimba, de Gianfrancesco Guarnieri, e Chico-Rei, de Walmir Ayala. Devido à sua relativa representatividade, o TEN serviu de modelo para outros grupos. Em São Paulo, Geraldo Campos criou, em 1946, o equivalente do grupo carioca, adotando o mesmo nome (5). Em Porto Alegre, Heitor Nunes Fraga fundou um grupo de "Teatro do negro". Em Santa Catarina, também se cogitou a possibilidade de se fundar um grupo nos moldes do grupo carioca.

O TEN não se restringiu a desenvolver atividades artísticoculturais, adquirindo uma dimensão mais ampla de atuação no campo político, social e intelectual. Uma das primeiras atividades desenvolvidas pelo grupo foi o curso de alfabetização. Além de atacar o analfabetismo, um problema crônico na comunidade negra, o curso visava a oferecer condições mínimas para que as pessoas pudessem integrar origem afrobrasileira e, de forma polifônica, assumiu uma conotação político-ideológica. Nas páginas de Quilombo, outrossim compareceram denúncias de discriminação racial, como o caso de instituições beneficentes, casas de caridade e orfanatos que só atendiam pessoas de "cor branca" (6). Da mesma maneira, algumas instituições de ensino foram criticadas, pelo jornal, por não aceitarem a matrícula de estudantes negros.

Em 1949, ocorreu uma dissidência no TEN. Descontentes com o autoritarismo de Abdias do Nascimento e a orientação artística do grupo, Haroldo Costa e outros integrantes resolveram montar uma nova companhia teatral, denominada preliminarmente de Grupo dos Novos, em seguida, Teatro Folclórico Brasileiro (7). Nesse mesmo ano, o TEN criou o Instituto Nacional do Negro (INN), um departamento de estudo e pesquisa sob a coordenação do sociólogo 


\section{Artigos \& Ensaios}

Guerreiro Ramos. Como o racismo gera problemas emocionais nas vítimas, como o do complexo de inferioridade, o INN criou os Seminários de Grupoterapia. A ideia era qualificar pessoas capazes de organizar grupos de teatro voltado para a cura dos complexos emocionais da "gente de cor" nos morros, terreiros e associações específicas, utilizando o psicodrama - um método terapêutico que produz efeitos catárticos no indivíduo.

Outra preocupação do TEN era dialogar com o mundo acadêmico, estabelecendo canais de interlocução com instituições de pesquisas, agências de fomento e intelectuais especializados nos estudos afrobrasileiros. A expectativa era de que o negro deixasse a condição de objeto e vislumbrasse ser sujeito dinâmico desses estudos. Mais ainda: que as tradicionais abordagens fossem substituídas por pesquisas conectadas aos anseios de soluções concretas para o problema do negro. Nessa perspectiva, o TEN colaborou com a Convenção Nacional do Negro, em 1945-1946, e organizou a Conferência Nacional do Negro, em 1949, e o Primeiro Congresso do Negro Brasileiro, em 1950, reunindo intelectuais como Edson Carneiro, Darcy Ribeiro e Roger Bastide.

Ainda em 1950, Abdias do Nascimento, a principal liderança do TEN, lançou sua candidatura a vereador do Rio de Janeiro, pelo Partido Social Democrático (PSD). A incursão de Abdias na política partia do princípio de que a luta a favor da população negra também tinha que ser travada no campo político-institucional. No entanto, o projeto político de Abdias naufragou. Quando se aproximava a data das eleições, descobriu que o PSD havia transferido à revelia sua candidatura para a chapa de deputado federal. Abdias ficou inconformado e, após concluir que não teria chances de ser eleito, decidiu retirar a candidatura (8).

Aquela foi a fase mais importante do grupo, quando adquiriu sede própria, empenhou-se pela implantação do Museu do Negro, encenou algumas montagens nos grandes teatros do Rio de Janeiro e realizou concursos de beleza. Há informações de que, até aquela época, apenas mulheres brancas participavam dos concursos de misses. Para se opor a essa forma de discriminação racial, o TEN promoveu concursos de beleza com a participação exclusiva de muIheres de cor. Os concursos receberam o nome de Rainha das Mulatas e de Boneca de Pixe. Foram realizados cinco desses eventos. As primeiras colocadas chegaram a emplacar uma carreira artística, ao menos foi isso o que ocorreu com Mercedes Batista, jovem dançarina aclamada Rainha das Mulatas de 1948. Com a intermediação do TEN, ela conseguiu, mais tarde, uma bolsa de estudos para fazer o curso de aperfeiçoamento de dança nos Estados Unidos e, quando regressou ao Brasil, criou o balé Mercedes Batista.

As mulheres não foram negligenciadas na trajetória do TEN. Arinda Serafim foi a principal liderança feminina. O jornal Quilombo reservava uma coluna específica intitulada "Fala mulher", na qual a articulista, Maria Nascimento, procurava ser porta-voz dos anseios da mulher negra (9). Com posições avançadas, ela defendia que as "patrícias" deveriam sair candidatas aos cargos eletivos e, ao mesmo tempo, adotar o voto de "raça" e "gênero" nas eleições de 1950. Foi a partir daquele ano que o TEN colaborou na criação de duas organizações: a Associação das Empregadas Domésticas e o Conselho Nacional das Mulheres Negras. Esta última desenvolvia um trabalho educacional e assistencialista, ajudando a comunidade negra na resolução de problemas cotidianos ligados ao exercício da cidadania.

POLÊMICAS O TEN primou por protagonizar ações polêmicas, as quais tinham repercussão na imprensa. A finalidade era chamar a atenção da opinião pública para o problema do afrobrasileiro. Dentro desse espírito, em 1955, o grupo promoveu o concurso de artes plásticas que tinha como tema central "Cristo negro". Os concorrentes teriam que, necessariamente, apresentar uma obra de arte em que fosse feita alusão a um Jesus Cristo negro. A intenção era questionar a representação convencional de Jesus Cristo: um branco de padrão estético eurocêntrico. Do ponto de vista da controvérsia, o concurso foi um sucesso (10). Cerca de cento e seis trabalhos foram inscritos, de pintura, escultura, desenho, entre outras linguagens artísticas. O vencedor foi Djanira, com a obra "Cristo na colina", evocando um negro no pelourinho escravocrata.

Na década de 1950 o TEN deu os primeiros sinais de crise, não conseguindo montar os espetáculos com regularidade. Com pouco espaço na cena teatral carioca, o grupo resolveu se transferir para São Paulo. A estreia na capital paulista se deu com a remontagem de O imperador Jones, de Eugene o'Neill, no Teatro São Paulo. Na "pauliceia desvairada", o grupo reivindicou receber uma subvenção por parte do governo municipal e estadual, mas não foi atendido (11). Sem a mesma força cultural de antes, a troupe regressou para o Rio de Janeiro. Após a instauração da ditadura militar, 


\section{Artigos \& Ensaios}

em 1964, a crise foi intensificada. Apesar das dificuldades, ainda foi possível levar a cabo o projeto do Museu de Arte Negra. Em 1966, o Ministério das Relações Exteriores impediu o grupo de apresentar a peça Além do Rio, de Agostinho Olavo, no Primeiro Festival Mundial de Artes Negras de Dacar, no Senegal. A alegação foi de que o trabalho do TEN não era representativo da cultura brasileira. Abdias do Nascimento organizou protestos no país e denunciou o fato para a Unesco e para o presidente do Senegal. No entanto, tudo foi em vão.

A precariedade financeira, os problemas internos do próprio TEN, a ausência de apoio institucional, o personalismo e o autoritarismo de sua maior liderança, a falta de respaldo político e cultural quer da comunidade negra quer da sociedade mais abrangente - incluindo, evidentemente, a da classe artística - foram fatores que levaram ao esvaziamento e à debilitação do grupo. Diante de um TEN moribundo, a ditadura militar, com sua carga de repressão e patrulhamento político-ideológico, não teve maiores dificuldades de preparar o terreno que impulsionou o golpe letal. Qualquer movimento em defesa dos negros passou a ser visto com desconfiança. Como resultado, o grupo foi praticamente extinto. Em 1968, Abdias do Nascimento partiu para o autoexílio nos EUA, semanas antes do anúncio do Ato Institucional no. 5.

O TEN procurou inovar a cena teatral sob vários aspectos. Além de abrir espaço para o ator negro no teatro brasileiro, engendrou a proposta de produzir uma dramaturgia centrada na cultura e nos problemas dos afrobrasileiros (12). O projeto era arrojado: afirmar o negro como ator, diretor e por vezes autor. O grupo não só conseguiu colocar no palco da discussão a postura dos artistas, autores, diretores e empresários teatrais brancos, como ainda procurou sensibilizar alguns críticos e formadores da opinião pública de um modo geral. A troupe foi a responsável por revelar talentos como Ruth de Souza, Lea Garcia, José Maria Monteiro, Claudiano Filho e Haroldo Costa que, sem o TEN, dificilmente teriam ingressado na carreira artística.

Colocando a arte a serviço do movimento de valorização política, social, cultural, intelectual e moral da população negra, o TEN insurgiu-se contra o silêncio que pairava no país em torno das questões e reivindicações desse segmento populacional e, em alguns momentos, o grupo pautou na imprensa e na agenda nacional o debate sobre o racismo à brasileira.
Petrônio Domingues é doutor em história pela Universidade de São Paulo (USP), professor adjunto do Departamento de História da Universidade Federal de Sergipe (UFS).Email: pjdomingues@yahoo.com.br

\section{NOTAS E REFERÊNCIAS BIBLIOGRÁFICAS}

1. Quilombo. Rio de Janeiro, 12/1948, p. 1.

2. Nascimento, Abdias. "Teatro negro no Brasil: uma experiência sócio-racial”. In: Revista Civilização Brasileira (Caderno Especial). Rio de Janeiro, no. 2, pp.193211. 1968

3. Müller, Ricardo Gaspar. "Identidade e cidadania: o Teatro Experimental do Negro”. In: Dionysos (Edição especial sobre o Teatro Experimental do Negro). Rio de Janeiro, MinC/Fundacen, no.28, pp.11-52. 1988.

4. Nascimento, Abdias (org.). Drama para negros, prólogo para brancos. Rio de Janeiro, Teatro Experimental do Negro, 1961.

5. Douxami, Christine. "Teatro negro: a realidade de um sonho sem sono". In: AfroÁsia. Centro de Estudos Afro-Orientais (UFBA), 25-26, pp.313-363. 2001.

6. Quilombo. Rio de Janeiro, 06-07/1950, p.8.

7. Costa, Haroldo. "As origens do Brasiliana". In: Dionysos (Edição especial sobre o Teatro Experimental do Negro). Rio de Janeiro, MinC/Fundacen, no.28, pp.139143. 1988.

8. Pinto, Luiz de Aguiar Costa. O negro no Rio de Janeiro: relaçôes de raças numa sociedade em mudança. Rio de Janeiro, Ed. UFRJ, p.250.1998.

9. Quilombo. Rio de Janeiro, 05/1949, p. 8.

10. Jornal do Brasil. Rio de Janeiro, 26/06/1955.

11. Diário da Noite. São Paulo, 13/04/ 1953.

12. Martins, Ieda Maria. A cena em sombras. São Paulo, Ed. Perspectiva. 1995. 